\title{
National Identity, Historical Consciousness, and Historical Preservation
}

\author{
Tracey L. Thompson \\ University of The Bahamas \\ Kenyetta T. Dean \\ Central Bank of The Bahamas ${ }^{1}$
}

... a person's identity, a person's understanding of their role in the world, a person's self-esteem, a person's consciousness-all of that stems from their idea of what their story is. And so your story pretty much inspires you, propels you forward-or not. - Ean Maura

\begin{abstract}
Bahamians are a people of increasing heterogeneity. The experiences of Bahamians of all backgrounds would profit from greater scholarly exploration. In any such undertaking, utilizing extant "hidden" archival collections and capturing oral history narratives is essential, as the challenge of documenting the historical experience of the African-descended Anglophone majority of Bahamians makes plain. Libraries can play a leading role in reducing the risk of losing hidden collections and oral narratives. That much is clear from the investment that the University Libraries of the University of The Bahamas have made in hosting "From Dat Time": The Oral \& Public History Institute of the University. Collaboration among cultural heritage institutions can accelerate the pace of bringing hidden collections to light and generating oral narratives. Technological advances enable us, meanwhile, to offer broad access to disinterred collections and captured oral history narratives. We can develop models of accessing such data like Ramble Bahamas that strike the right balance among competing imperatives of fostering education and research, of generating revenue, and of strengthening national heritage institutions.
\end{abstract}

\section{Telling Our Story}

Among Bahamians, when matters in question fall within the geographical boundary of our archipelago, island credentials as much as national identity claim the loyalty of many of our citizens. Whether from Grand Bahama or Abaco, or from Long Island or Andros, or from Acklins or Ragged Island, men and women form social attachments based on island kinship, tout the virtues of their particular isle, and vie to advance its interests. In addition, through longstanding distinctions in how we distribute wealth and opportunity in our community, our populace lies fractured

\footnotetext{
1 Tracey L. Thompson, "FDT": The Oral \& Public History Institute, University of The Bahamas, Nassau, Bahamas and Kenyetta T. Dean, Librarian, Central Bank of The Bahamas, Nassau, Bahamas.

E-mail: tracey.thompson@ub.edu.bs

Acknowledgements: Elements of this article relating to libraries and to collaboration were presented as a paper at the 2014 Annual Conference of the Association of Caribbean University Research and Institutional Libraries (ACURIL). The authors thank colleagues who contributed information for that paper, notably Elaine Toote, Berthamae Walker, Patrice Williams, and Sherriley Strachan. The authors also thank Ean Maura, Prescott Smith, Sharon Poitier, Philip Simon, and Nia Bethel-Sears for ideas contributed to this article at a "FDT" Summer 2017 Think Tank Series conversation organized by The Heritage Partners consulting group on June 30, 2017.

APA reference: Thompson, T. L., \& Dean, K. T. National identity, historical consciousness, and historical preservation. International Journal of Bahamian Studies, 23, 49-66. https://doi.org/10.15362/ijbs.v23i0.280
} 
into distinct economic and social groupings. Billionaires and millionaires carry Bahamian passports; so do men and women whose only resource is their employment income; so do inhabitants who have no means whatever of support. Further, our citizenry grows more and more diverse in language, culture, religion, and race as an outcome of our quest to draw financial capital and answer labour needs, an outcome of efforts by refugees from other communities to seek safe harbour in the islands, and an outcome as well of romantic linkages. Joining the West African and Northwest European land- and slave-holding, mercantile, enslaved, peasant, and workingclass inhabitants who formed the nation's early demographic core have come families and individuals from other parts of the world: from Greece and Syria, to China and Russia, from Haiti and the United States, to the Philippines and Peru (Glinton-Meicholas \& Curry, 2004; Williams, 1996, Tinker, 2011). In The Bahamas at the outset of the 21st century, our archipelagic community is marked by variety in island affiliation, wealth and income, national origin, language and culture and religion, and racial category.

The historical undertakings of Bahamians of all these geographical, socioeconomic, and cultural and racial niches cry out for further oral and documentary excavation, for while a swelling body of biographies, memoirs, reminiscences, and historical treatments and commentaries (see examples in Appendix A) does help us to reconstruct the texture and variety of life across our archipelago as it was lived prior to our exposure to television and internet, and while much work has been done since Collinwood lamented, in 1981, the severe shortage of scholarly inquiry relating to the evolution of Bahamian society (see examples in Appendix B), the corpus of monograph-length works which cast the light of critical scholarship upon our values, our choices, our initiatives, and our lifestyles over the course of time is still relatively small. We continue to await the development, by means of a radical expansion in the number of professional historians working in the field, of a body of scholarly literature that is substantial in volume and that sets before our eyes descriptions and explanations of how life in our archipelago has unfolded that are intimate and yet extensive. They are intimate in the sense that they are evocative of local time and place, situating events on particular days or weeks or months and placing them on particular streets or in particular neighbourhoods or settlements. They are extensive in the sense that their explanations of even the most local of undertakings link decisions that are taken in places far afield: across a region, a hemisphere, an ocean, perhaps even a globe. Crucially, these are explanatory narratives that render our children's forebears as subjects and agents of the story and in as much visibility as sources permit. These narratives pinpoint, as being the object that calls for explication and explanation, those forebears' own sense of their lived experience as they faced their priorities and their dreams, their aspirations, their options, their choices, their accomplishments, their losses, and their sacrifices. These are narratives which, considered collectively, are broad in thematic range; which use "thick description" (Geertz, 1973) to help us to account for shifts in relations of power, in ways of life, and in the values that underpinned those lifeways; and which are inclusive in that they allow as many different voices to be permitted to speak into our collective hearing as is feasible. One observer points out that "it is vital that we hear the voices of ordinary people, both because their voices have value on their own terms but also because often their voices bear the truth about a situation" (S. Poitier, personal communication, June 30, 2017). In spite of the challenges presented in some 
instances by a paucity of sources, the development of such an historiographical tradition, raised by more and more practitioners on the foundation already laid by our a gallant band of pioneering authorities, must be the central project of Bahamian historical scholarship.

The principal reason why we need such narratives is that such narratives help us to make sense of the human world in which we live. Answers to questions such as where we and others came from, and what we and others came from, and what we and others valued and wrought, and how it has come about that we and others inhabit, today, the places where we live, and why we and others play, today, the roles in society that we do play leave us feeling assured that the world does have coherence and rationale. Answers to questions of how people once thought and acted also leave us able to interpret more accurately thinking and behavior that we meet with in people today, as one observer notes, including leaving us better able to construe, when doors open before us and when doors close before us, the reasons why (P. Smith, personal communication, June 30, 2017). As a sense that the world does have order and rationale and a sense of understanding the world replace a sense of isolation and a sense that speaking and action take place at random, and as an understanding of meaning and motivation replaces bewilderment and confusion, then one can move in the world with deeper quietude, with greater confidence in one's interpretations, and with more effectiveness in pursuing one's objectives. The more detailed and elaborate the historical explanation that we can bring to bear on not only our everyday encounters but also the origin and character of the entire social order which surrounds us, moreover, the deeper our quietude, confidence, and sense of efficacy and the more we can maintain our equilibrium balance. By contrast, without such explanatory narratives that account to us comprehensively for what we observe and what we experience, we suffer severely. In one perceptive view, we thirst for meaning and explanation and order as part of creating and maintaining our sanity; without interpretive and explanatory narratives we cannot make sense of what we experience; and the year-in and year-out inability to bring rationale and order to our encounter with the world gradually comes to constitute psychic abuse. Abuse naturally foments frustration and anger, which lead, as expressions of those feelings, to violence in various forms (J. P. Rolle, personal communication, 2017). If this view should be correct, then for greater peace within and greater peace without, the past as a source of explaining to us the reasons for our everyday experience is where we should look.

Inner peace grows all the more when we bring knowledge about our past to bear upon a project just as important as apprehending order in the world and making sense of our experience: the project of mapping who we are. How we work out who we are-that is to say, how we make our "selves" ever more visible to our selves-is by successive acts of placing ourselves in relation to these places in space, and those moments in time, and these people, and those projects. But we cannot carry out this process of articulating our selves if we know of no places and moments, no people and projects, no dreams and aspirations and endeavours and causes; while, conversely, the more knowledge we have of such phenomena, the more richly, even gloriously, we can elaborate our selves. The past is a reservoir of phenomena without parallel, what with its centuries and millennia of people with whom we may identify, and its times and places and situations and ideas in relation to which the curious and persistent mind can position itself and work out for itself its commitments. We know who we are when we commit ourselves to a foothold in the 
unfolding human story. However the past, if it would be visible to us at all, must first be remembered. Above all, untold stories of our own place and community must be resurrected and given voice. If the places where our own forebears have thought and acted lie unnamed, and if the stories of their visions and ventures lie unspoken, then the world that is closest to us is silent when compared with how rich with intricacy and eloquence it might otherwise be, and the store of material that we need for thinking about what surrounds us most closely and how we might position ourselves in relation to it is impoverished. Our connection to site, village, settlement, neighbourhood, town, country, living person, ancestor, historical personage, and community are left tenuous, and the soul that clamours for attachment in place and in time and anchoring in purpose remains restless, the mind that reaches for content on which to reflect so as to utter its most intimate self is left dissatisfied, the voice that seeks to speak its most fertile vision lies mute, the spirit that seeks to honour its call to relevance and contribution is left deflated, and frustration and lack of direction rather than stability and orientation mark the journey that seeks after fulfillment and peace. ${ }^{2}$

Not only peace but also safety both individual and collective, both spiritual and material, flow from gaining acquaintance with patterns of human thought and action that have found expression in the past. As human beings we are capable of treating one another kindly and of treating one another cruelly. Historical narratives illustrate that truth, setting before us instance upon instance of faithfulness and

\footnotetext{
2 Many talented young Bahamians spend valuable time and energy searching for answers to their questions about the historical experience that defines them and their community. Unfortunately the answers that they seek prove to be elusive because so much of that historical experience remains untold or, if told, largely inaccessible. (N. Bethel-Sears, personal communication, June 30, 2017)
}

treachery, sacrifice and selfishness, joy and tragedy, and opportunity seized and opportunity lost, as well as examples of how complex may be the circumstances which people face and how hard may be the choices that they have to make. Familiarity with this showcase of the human spirit helps us to meet the challenges of our own lives with more perspective, more insight, and more fortitude. It helps us to turn more readily from invitations to despair and to dishonour. It offers us tools for inspiring ourselves and our children to positive values and moral behaviour-in a word, for civilizing ourselves. In these ways it strengthens us and our community spiritually. And then there is the question of protecting self and community in practical terms. The same evil that we find in individual interaction is plain to see in the historical record of group interaction as well. If as a community we would safeguard ourselves from exploitation we must recognize the meanings of economic and political agendas that contend for our acceptance. The past is where to turn to find patterns of thought and action that help us to construe, in spite of deliberate mystification, where our true interests lie as a community and to set priorities that are intelligent rather than trivial (P. Smith, personal communication, 2006 and June 30, 2017). Of special importance too, if we would safeguard ourselves from abuse, is that we be the ones to craft the very tool that enables us to order our world, to declare who we are, to live purposefully and honourably, and to navigate our global environment intelligently. We ourselves must be the ones to tell the story that defines us and all that surrounds us. If we fail to tell our story, others will certainly do (P. Simon, personal communication, June 30, 2017). In a world that is fractious, competitive, and often vicious, and in which the notion that some people are disposable has stood on full display, to leave to others 
unchallenged space to impose on our minds images of ourselves that are hostile to our well-being and that limit our sense of our possibilities invites us to stand vulnerable and to live in jeopardy. History, that reservoir of phenomena, is also that reservoir of instruction whose lessons offer guidance and security.

\section{The Value of "Hidden Collections" and Oral Narratives: A Case In Point}

If we are to stitch together an explanatory tapestry of our community's evolution that answers to our needs, then the scholarship that presents such transformative explanations will need to draw upon what librarians call "hidden collections" to complement more public historical sources such as newspapers and government documents or more formal sources such as church and other institutional documents. Hidden collections of artifacts, recordings, and documents, often lying in the possession of individuals and families and community organizations, are ones that hold enduring historical or other cultural value but have not been identified, or have been identified but not acquired, or have been acquired but not processed and integrated into publicly accessible collections. Many are the families, of all racial identifications and cultural and socioeconomic backgrounds, who cherish photographs taken of lineage members, and some families boast photographs which carry broader social significance. Some families, too, have papers which can fill gaps or open new fronts in our analyses of our past. If we move with speed in the face of human accident and natural disaster, we can preserve these hidden collections. Furthermore, since much of recent Bahamian experience is still held, and only held, orally, these explanatory narratives will also need to draw on oral histories. Many are the Bahamian elders who now are in their 80s or older in age, who live in urban settings in Nassau or Freeport or in smaller communities dotted through the Family Islands, and who are able to recall norms of behavior, styles of expression, and ways of meeting basic needs that were current only 50 years ago and that are now alien, the memory of them fast fading from public view in light of the speed with which shifts in communication and transportation and other technologies are changing lifestyles and recalibrating relations of power. While death has claimed many, many more elders who could have shared with us unique information about specific developments that warrant explanation, there are still a sufficient number of elders among us to gather, if we hurry, data that can help us to tell a rich and compelling story. The task at hand is to mobilize resources swiftly to uncover and analyze hidden collections before they are lost and to capture oral narratives before the voices of their bearers fall silent.

To bring into view more clearly the value of hidden collections and oral narratives for fleshing out our collective story, consider the challenge of documenting the historical experience of the African-descended Englishspeaking majority of Bahamians. Not all older Bahamian families are descended from Africans: conventionally speaking, today some $15 \%$ of Bahamians can fairly be classed as being descended primarily from Europeans, and in addition there is a small percentage of Bahamians who first came to The Bahamas in the late 1800s and are probably most easily categorized as being of eastern Asian and of western Asian descent. What is more, a significant number of African-descended Bahamians have relatively recent roots in neighbouring Haiti and linguistically speaking are Francophone or are bilingual. As a result, the story of the Anglophone Africandescended Bahamian, while critical and compelling, is far from the complete story of our national unfolding. Still, today, even amid the growing diversity of our community, the great majority of Bahamians are people whose 
ancestry does lie primarily in Africa and whose mother tongue is Englishdemographic and cultural facts that reflect more than 300 years of historical development in the archipelago, occurring within the context of an Atlantic-wide political economy (Butler \& Smith, 1983, Craton \& Saunders, 1992). With respect to this demographic majority, a body of critical historical exposition that matches the scope of its experience is still wanting. Hidden collections and oral narratives can prove powerful aids to creating that extensive body of scholarship.

That is because one of the reasons for the shortfall in critical historical analysis likely rests with availability of written and visual sources. The character of Africans' presence in the archipelago militated, surely, against their writing down their reflections and views. Like their counterparts across the hemisphere, they came not of their own volition but rather through the violence, ultimately, of largescale European capitalist investment in the Americas. Sources make plain that ship after ship plowed the waters of the Atlantic ferrying Africans westwards to toil in agribusiness, mining, maritime, and other natural resource industries that were controlled by European monarchs and merchants and bankers and planters and that transformed the land and the peoples of the hemisphere. The systems of coercion that pulled Africans across the ocean in vessels captained by the likes of a Manoel Calvo and a Nat Ingraham and an R. Kelly ${ }^{3}$ typically forced them into manual labour, appropriated the wealth that they produced, placed them at risk of separation from family, excluded them from control of public resources and contribution to public decision-making, and limited their opportunities to learn to read and

${ }^{3}$ Captains' names are drawn from the Trans-Atlantic Slave Trade Database (www.slavevoyages.org). The examples selected relate particularly to landings of captive Africans in the Bahamian archipelago. write. Regimes of work, economic exploitation, physical separation, political exclusion, and denial of education, imposed both during formal slavery and after the collapse of that legal apparatus of abuse and control, could only add up to difficulty in transmitting specific knowledge and recollection along a chain of generations. For reasons of history, in The Bahamas the 350year-old documentary record little registers the voices of Bahamians of African descent.

Inevitably, reverberations of this historical subordination can be traced in the holdings of Bahamian national repositories. The Department of Archives, established in 1971, is mandated to house public records. In alignment with that mandate, the professional team of the Department, even though fettered by severe resource constraints, has assembled impressive collections of public documents and other materials. In character these collections bring into focus the conduct of government and the evolution of society throughout the island chain, and in format they include writings, maps, plans, and photographs. Further, with foresight and initiative the Archives team solicited deposits from notable private citizens and significant private institutions early in its development, with the result that today the Archives houses a significant number of non-governmental collections. Papers, photographs, memorabilia, books, and articles appear in these private deposits, and they lend insight into the transactions and affairs of religious entities, Family Island communities, and individuals. These treasuries of public and private materials do offer, some of them, not only evidence of agency exercised by Bahamians of African descent but also expressions by African-descended Bahamians of their views, their perspectives, their philosophies. Examples of such materials are The Citizen's Torch, contained in the deposit of Dr. Cleveland Eneas, himself a product of 
Bain Town-a community of Yorubas from what is today Nigeria and their descendants (Eneas, 1976; Saunders \& Carson, 1980, p. 38); The Freeman, a newspaper characterized as being the "voice of the coloured people" (Williams, 1999), which is to be found in the deposit of Mr. Paul Adderley; and the papers of Sir Milo Butler Sr., the nation's first Governor General and the first black representative of the British Queen (Saunders \& Carson, 1980). But it remains the case that the considerable bulk of the written holdings of the Department of Archives express the voices of a British colonial elite and Bahamians of European descent and that the voice of the Anglophone African-descended Bahamian has been disproportionately silenced.

An aggressive effort on the part of the community to deposit hidden collections in the Department of Archives and other public repositories can bring to light much more of the reflection and experience of Anglophone African-descended Bahamians. There is a need for haste, to be sure, because such documentary expressions of Anglophone African-Bahamian voices as remain in private hands are continuing to be lost. One hears again and again of miscalculations and mishaps that precipitate the destruction of valuable sources. Thus in 2004 winds and accompanying rains brought by Hurricanes Frances and Jeanne in Grand Bahama blighted private-and public too-assemblages of documents (Economic Commission for Latin America \& Caribbean, 2004; E. Toote, personal communication, 2014; Family of J. Thompson, personal communication, 2014). Either Hurricane Joaquin of 2015 or Hurricane Matthew of 2016 destroyed the office of the Island Administrator in Acklins and with it a map which had laid out landholdings of extended family clansinformation that is proving challenging to reconstruct (F. Robinson, personal communication, 2017). A fire that took place at the headquarters of the first enduring political party in The Bahamas is said to have destroyed a considerable number of valuable materials. A fire that took place at the headquarters of the Ministry of Tourism destroyed the Ministry's papers and with it the written record of the evolution of the institution that guided the economy of The Bahamas in the post-World War II era. February 2014 brought news of a matron who, reluctant to continue to house a suitcase and boxes filled with papers belonging to her deceased grandfather, ultimately burned the collection. Those documents, it would appear, might have cast significant light on how Bahamians of African descent used lodges to strengthen their communities. April 2014 brought news that the papers of one of the active participants in the defining struggle in the 20th-century Bahamas to bring about societal change had fallen prey to a nest of rats. Further news came in that same April: that the papers of a steadfast participant in the labour movement, boxed and placed in his garage until such time as he could draw upon them for a history of the movement, were thrown away by a son who did not know their purpose and value. Against these disappointments one hears of private collections that are being successfully preserved, but these collections may tend to express the voices of Bahamians of coloured middle-class rather than black working-class origins. If public and private players act soon to stem the tide of loss, particularly as concerns evidence relating to working-class African-descended voices, the body of evidence that is available to scholars regarding Anglophone African-descended Bahamian thought can grow significantly.

The same opportunity to preserve vulnerable evidence that summons us to collect written documents bids us also collect oral data. Consider the need to document the struggle 
for majority rule and the advent of national independence. Together, those developments transformed social and political relations among Bahamians and between Bahamians and the world. They are two of six or seven epochal events to have taken place in the modern experience of the island chain, standing alongside the destruction of Lucayan communities in the early 1500 s, the resettling of the islands in the mid-1600s, immigration from the new-born United States of America and the new-born Haiti at the turn of the 19th century, and the dismantling of formal slavery in the early 1830s. These two transformative moments have taken place within living memory, and contemporary technology permits us to capture the recollections of key participants without difficulty. Yet we have allowed most of the protagonists and informed observers, whether of European or African or mixed descent, to pass on without any concerted move to record their experiences and views before they were laid to rest. Consider, again, the project of documenting the evolution of maritime industries in an archipelagic nation. In the fly fishing arena, for instance, with rare exceptions older fly fishermen have carried their stories with them to their graves and younger practitioners stand in peril of doing the same. To be sure, there is some good news. In regard to our cultural traditions, $\mathrm{Mr}$. Charles Carter, proprietor of the Island FM radio station, has for years interviewed artists and sportsmen among others, and he has assembled an enviable archive of recordings. In addition, the Department of Archives, recognizing the lacuna prevailing in the area of oral sources, began more than 40 years ago to develop an oral history collection, and that collection gives voice to the experiences, perceptions, reflections, and judgments primarily of African-descended Anglophone Bahamians. In comparatively recent times the Department's efforts have been supplemented by biographical interviews produced by the Broadcasting Corporation of The Bahamas and by Cable Bahamas in two television series called, respectively, Legends and Portraits. However these various initiatives, while intensely valuable, are small in scale relative to the need systematically to render a Bahamian way of life that is, under the impact of new technologies, fast disappearing. The moment is ripe for us to seize the opportunity to accelerate dramatically the pace at which we interview and record Anglophone Africandescended Bahamian elders so that we can augment the body of data that expresses their distinctive voice.

\section{Libraries as Agents of Historical Preservation}

In the quest to enlarge the volume of historical sources relating to Bahamians of all backgrounds and so make possible a richer Bahamian historiography, Bahamian libraries have a central role to play. The Ministry of Education, Science and Technology maintains school libraries and community libraries across the length of the Bahamian archipelago. In addition to these publicly funded institutions, community libraries that are supported primarily by private funding have also been established. The result is that in the center and the east of the archipelago, New Providence features 11 libraries, Exuma one, Harbour Island and Eleuthera a further 11, Cat Island two, and Long Island and San Salvador one apiece. In the west, Andros, the Berry Islands, and Bimini each maintain one library. In the north, Abaco boasts five libraries and Grand Bahama four. In the south, Acklins, Crooked Island, Long Cay, Inagua, and Mayaguana are together served by seven libraries. This network of centers of literacy and learning offers a valuable platform for cultivating in our citizenry an appreciation for community and national heritage. Each unit can serve as a powerful base for activities that contribute to preserving cultural heritage. 
Among those activities can be the solicitation and deposit of hidden collections and the identification and interrogation of bearers of unique historical information that can light our unduly faint images of the historical worlds not only of African-descended peasant and working-class Anglophone Bahamians but also of their European-descended "conchy-joe" counterparts and of the migrants who have joined them more recently from around the world. Libraries can intervene to help us to tell, in its fullest and most accurate rendition, our national story

The University Libraries of the University of The Bahamas exemplify the kind of intervention that this archipelagic network can undertake. In 2012, the Libraries began to host a new initiative that was mandated by the governing body of the then College of The Bahamas and that built upon the College's earlier Oral History Department. That new initiative was the founding of an institute for oral and public history. Formally established in January 2013, "From Dat Time": The Oral \& Public History Institute (frequently called "FDT") aims to bring into being a new social reality based on widespread citizen consciousness of the Bahamian historical experience. Its focus lies with documenting Bahamians' worldviews and experiences and with producing educational products for popular consumption. As resources become available, the institute looks to interview hundreds-even thousands-of Bahamians in order to capture the richness of the Bahamian experience locally and abroad during the 20th century. Themes ranging from social relations in individual industries to traditional methods of healing, from assumptions about nature to military undertakings, and from recreational practices to the evolution of national institutions are to be brought to Bahamian children-and to world audiences-in curricular and recreational materials. The process of planning the Institute has required a base of operation, and the established entity has required a home. The University Libraries have provided that base and that home, and its Bahamian Special Collection will be the recipient of the recordings produced by institute staff. The Libraries' hospitality in offering shelter to the institute presents a model for libraries around our archipelago to support efforts to record our elders' knowledge. Those libraries in turn can become repositories for those recordings, safeguard them, and make them available to the Bahamian public.

The value of such an initiative for preserving oral history and educating Bahamian children is apparent from the impact of the Library's previous oral history undertakings. In 1990, the then College of The Bahamas Library launched an Oral History Department. That Department embarked on three research projects: exploring racial and cultural diversity within the island of New Providence, investigating the experiences of Bahamians who had travelled to the United States on "The Project" (also known as "The Contract") to work in agricultural industries, and participating in research on Bahamian culture that was geared towards Bahamian involvement in a folklife festival mounted by the Smithsonian Institution in Washington, D.C. The second of those three initiatives, entitled "Remembering The Contract," yielded an array of products for public enjoyment: a video documentary that was broadcast on local television; a photographic exhibition that was displayed at the national central bank; a set of commemorative postage stamps that was issued by the Post Office Department; a musical production that was mounted at the local centre for the performing arts; a painting produced by world-famous Bahamian artist and former "Contract" worker Amos Ferguson; a distinguished lecture presented by a Florida-based veteran of "The Contract"; a radio programme that aired on 
national radio; and an academic paper (Thompson, 2012). What is more, ultimately "The Contract" entered the curriculum as a topic for national examination. Young Bahamians' awareness of "The Contract" has grown as a result, and in this way the Library has helped to address the challenge of anchoring young Bahamians in an understanding of the collective Bahamian story.

The value of such an initiative not only for deepening historical consciousness but also for increasing library revenues ought also to be recognized. Libraries and other cultural heritage institutions, when they hold unique collections, are stewards of great wealth. They can monetize their collections-that is, find ways to translate that wealth into cash while yet retaining ownership of the collections in which the wealth inheres. Cash revenues can assist with meeting operating expenses as well as current and future preservation and conservation expenses for their collections. Historically, to be sure, heritage institutions have not considered monetization as a method of sustaining their continued existence. However that posture is changing. Three years ago, for example, the Detroit Institute of Art faced extreme financial challenges, and as a result there was ongoing pressure for it to sell its collection to recoup cash to pay creditors while also ensuring that the items making up the collection should remain together (Wisely, 2014). Several scenarios were suggested as answers to their predicament, including using the art works as collateral for a financial loan, making temporary or permanent loans of the collection to other institutions, creating a trust that would allow other institutions to rent the works of art, and, lastly, mounting travelling exhibits of the collection (Wisely, 2014). With respect to The Bahamas, researchers located across the region and around the world, once alerted to unique collections held by Bahamian libraries and other cultural heritage institutions, may well travel to The Bahamas in order to carry out academic and independent research. Already researchers have travelled from abroad to the University of the Bahamas Libraries in an effort to consult its archive of recordings relating to "The Contract." Fees charged for access to the collections can help to support the institutions; and indeed the "intellectual tourism" that can flow from drawing researchers to spend extended time in the islands in pursuit of access to rare or unique collections can also lend a boost to the overall tourism economy. Bringing hidden collections to light and producing oral narratives can do more than foster perceptive scholarship: they can help institutions and communities to expand their incoming revenue.

\section{Accelerating Preservation Through Institutional Collaboration}

Given that accelerating the pace at which we preserve hidden collections and capture oral narratives is essential if we are not to lose them, one way to bring about that acceleration is through having institutions that operate in the cultural heritage arena collaborate with one another. In The Bahamas, local cultural heritage institutions, using their multiple sites for interacting with citizens in communities, their collective credibility, and their allied resources, could mount a comprehensive, systematic, and coordinated programme of identifying, acquiring, and processing hidden collections located across the entire archipelago and even abroad. On its own merits, of course, apart from for the specific purpose of enhancing the volume of historical sources that are available for scholarly inspection, collaboration has the potential to bring with it blessings such as economies of scale and more efficient allocation of resources which are key to securing savings, improving productivity, and improving service (Liu, 2002); and libraries have long 
exploited the possibilities of collaboration and partnership to maintain patron satisfaction while yet limiting expenditure, especially through coordinating systems so that patrons could borrow resources from any library in a given system (Chatterjee, 2002). But with respect to disinterring hidden collections and capturing oral narratives, collaboration could engender benefits that would be invaluable to the growth and progression of the community.

What if, for example, the papers of Dr. Claudius Roland Walker were to be deposited in the new Bain and Grant's Town community library established by the Bain Grants Town Advancement Association? Dr. Walker, described by a former governor-general of The Bahamas as being "a leading representative of the Over the Hill black community" (Turnquest, 2016), was an eminent Bahamian doctor, legislator, political activist, and public intellectual of the community of Bain Town in the mid-20th century. Among his many accomplishments were his building the Reinhard Hotel, a structure which hosted social events, housed business operations, sheltered progressive industrial and political movements, and helped to catapult the colony in 1967 to Majority Rule. The Department of Archives and the University Libraries could together lend the new Bain and Grant's Town community library professional guidance and expertise in organizing and processing the deposit; could digitize the collection so as to maintain a backup copy of it; and could further assist the library by training interested community persons for service in it (B. Walker, personal communication, 2014). Assistance of that professional calibre could allow the library to function at a level that enabled monetization of the collection, moreover, by means that included announcing its archive on a virtual catalogue and thereby making the archive more readily known to researchers and the general public worldwide.
A small fee could be levied for researchers who wished to consult the collection. Those monies could help the community library to defray its operating costs. Local inhabitants, visitors from other parts of the country, and tourists from abroad could be drawn to the library in order to see exhibits designed on the basis of the body of the papers contained in the "Walker Collection" and could pay an entrance fee. In this instance as in many others, collaboration could bring unique hidden collections to the public in polished style and in ever greater quantity; the number of monetizable collections could grow; and this increase in monetizable collections could in turn make possible for their host institutions an expanding stream of revenue.

The opportunity is there, then, for the Department of Archives, the University Libraries, and community libraries to place themselves on the front lines of accelerating the preservation of hidden collections and oral narratives. The Department of Archives and the University Libraries, each already home to deposits of previously hidden collections and each already engaged in the task of documentary and oral history preservation, could act in consultation with one another jointly to carry forward their preservation initiatives. Each would work in close association with community libraries, which would take the lead in identifying potential donors of hidden collections and bearers of oral narratives residing in their urban neighbourhoods or rural settlements and in soliciting those deposits and narratives, while their counterparts from the Department of Archives and the University Libraries lent advice and support. The University Libraries could provide assistance to community libraries engaged in this activity through attaching its professional staff to community libraries during summer months as a part of the staff's mission of community engagement. Professionally assisted by the Department of 
Archives and the University Libraries, community libraries might well become dynamic sites for library cadet training programmes that are already conducted by the Bahamas Library Service. If cultural heritage institutions, notably the Department of Archives, the University Libraries, and community libraries could come together in this way to work in synchrony to accelerate cultural preservation, not through the creation of an overarching "command and control" administrative superstructure but simply through highlighting the shared exigency of cultural preservation that unites them rather than emphasizing any differences that could divide them, the result of this sharing of expertise and resources could yield a dramatic increase in the pace of historical preservation.

The same institutional cooperation that can accelerate the pace of preserving our history and culture can also build our communities, if we make depositing each private collection in the library of the very community from which it emerges an important feature of our collaborative planning. That is because for community libraries to become principal stewards of sources relating to their communities and for community inhabitants to have ready access to those sources would be to kindle opportunities for those inhabitants to enhance their collective knowledge and self-esteem. Knowledge and self-esteem are nourished by learning about the aspirations and accomplishments of residents of one's community as well as about other cultural attributes like language, art, craft, dance, music, and oral traditions that may help to make one's community unique. Cultural programmes that bring these aspirations and accomplishments to the fore carry value, therefore. The basis of such programming lies with exploiting the very collections of documents and oral narratives, as well as other historical and cultural resources, of which community libraries are natural stewards. Community libraries can spearhead seminars and workshops in a variety of areas such as creative writing, fine and performing arts, genealogical research, and cultural preservation which draw direct inspiration from their previously hidden collections and their captured oral narratives. And to strengthen their delivery of these programmes, community libraries can draw upon their collaborative networks. Thus some of their workshops and seminars could be taught by cultural heritage professionals who were based in other institutions either as part of their professional responsibilities to their primary employers or through other frameworks that made for their sustained participation and commitment. In a ripple of benefits, such workshops would also help professionals to communicate the value of historical records to our citizenry and so help to arrest the destruction of those records. Such workshops would also encourage future generations of archivists, oral historians, curators and librarians to identify with and invest in their communities. Strengthening our communities, therefore, could be a major benefit that flowed from unearthing hidden collections and capturing oral narratives.

How, then, might we foster the collaborative ethos that can enable us to exhume hidden collections and generate oral narratives more quickly? A shrewd step towards encouraging partnering and collaborating would be to create avenues for young professionals entering individual institutions to spend time working in sister institutions. We can accomplish this through a system-wide programme of professional attachments. Of equal value would be the organization of collaborative inter-institutional projects led by young professionals. Proof that this kind of exposure fosters openness to and respect for collaboration is to be found in the experience of one of the co-authors of this article. As a graduate student in library and information 
science at the Pratt Institute in New York City, co-author Kenyetta Dean was a Project CHART recipient. Project CHART (Cultural Heritage, Access, Research and Technology, http://www.brooklynvisualheritage.org/), a joint venture of the Brooklyn Historical Society, the Brooklyn Museum, and the Brooklyn Public Library in New York City, aimed in part to train individuals for careers as digital managers in museums, libraries, archives, and other cultural heritage entities. Through her internship at the Brooklyn Historical Society, Ms. Dean participated in a collaborative project that provided access to hidden collections housed across the three Brooklyn institutions. The one-year internship afforded interns hands-on experience in document selection, digitization, description, access, and digital preservation; provided them with opportunity to develop a collaborative website, hosted at the Brooklyn Public Library, for digitized historic images drawn from the three partner institutions; enabled them to share Project results at conferences and symposia and through publications and the Project website; and more. The experience of working on a collaborative project involving a library, a museum, and an historical society exposed interns to the many benefits of collaboration as they prepared to become leaders in their future professions. For Ms. Dean at least, the experience of floating across institutional boundaries bred an appreciation for how sustained collaboration could foster opportunities for growth on the part of individuals and institutions alike.

\section{Enhancing Access through Digital Technology}

If we wish, we can carry previously hidden collections as well as oral history narratives to school students, teachers, the general public, and academic and independent researchers located across the Bahamian archipelago and indeed throughout the world. Digital technology is what can bring about this radical expansion of access. Documents, photographs, and analog voice and audiovisual recordings can all be digitized and then be projected through the internet to patrons around the globe. For Bahamian teachers located on our far-flung islands and cays, having at their fingertips a virtual library of resources that would enable them richly to illustrate their lessons would be a boon. For Bahamian students, being able to tap into such a library could breathe more life into subjects like history and geography. For researchers everywhere, such ready access to historical sources would undercut dramatically the cost of their practising their craft. That said, however, what is also the case is that libraries and other institutions which incur significant expense in identifying, assembling, processing, housing, digitizing, and uploading data need to recoup the value of their outlay if they are to be able to continue their work. What is more, those same institutions need time and freedom to develop their fledgling collections. Unlike their counterparts in places like the United States, the United Kingdom, and Canada, which, supported in part by revenues of formal and neocolonial empire, have had decades in which to amass unique cultural resources and the authority, prestige, influence, stature, and revenue-generating capability which accompany those assets, national cultural institutions in a country like The Bahamas have lacked equivalent opportunity to develop fully and exploit the wealth that inheres in unique cultural heritage resources. They are entitled to have that opportunity before they are confronted with having to forego the rewards of their investment. Even as the potential of technology for helping to meet national educational needs and facilitate local and international research should not be ignored, therefore, what is key, after we unearth hidden collections and generate oral narratives and 
are able to consider publishing them, is to find the balance that answers to competing imperatives of educating our children and facilitating research, generating revenue, and augmenting the wealth of our national heritage institutions.

One way of balancing those imperatives is to afford patrons access that is at once broad, in the sense that once they are able to enter internet space there is no pecuniary or other barrier to their utilizing the data that is presented there, and yet is selective, in the sense that only some of the archived data is presented to view. At the University Libraries, progress has been made in using this model of unfettered and yet selective access. Ramble Bahamas, a website which can be viewed on computers or on mobile devices, marries Bahamian history, digital media, and the internet (www.ramblebahamas.org). Built by Jessica Dawson, then Fellow in Research and Technology at "FDT", the Ramble Bahamas platform features exhibits curated by Ms. Dawson about historically significant places and objects in The Bahamas. Each exhibit comprises a narrative outlining the importance of the location or object, relevant historic and contemporary images, and oral history audio or video clips in which informed narrators speak of events associated with the location or object. For Ramble Bahamas "FDT" chose a dissemination model that incorporated free access because even though generating revenue was not an irrelevant consideration the principal aim of the initiative consisted in helping high school teachers of history to equip students with sufficient knowledge of Bahamian history to be able to use their college years to define and address their own questions in the field. At the same time, the institute chose to couple free access with selective presentation of data partly because teachers' limited classroom time and students' limited attention span argued for bringing brevity and variety rather than length and possible monotony to the website's presentation of historical knowledge. Another reason for making this choice was that in a small community concerns of privacy always merit special attention, and where privacy seemed to be in need of protection it could be preserved by extracting excerpts from interviews. A third reason for making this choice was that in time, so "FDT" anticipated, the institute would offer a data archive that would present complete or near-complete recordings of many of the interviews from which Ramble's audio excerpts drew. That archive would meet the needs of researchers and students whose appetites for more information had been whetted by their exposure to Ramble. A final reason for this choice was that an approach to data dissemination that combined free access with data selectivity would preserve for the University Libraries the freedom to determine whether, in the future, the Libraries would make those source recordings available to the public at no cost or at a fee. In this way, between the pull of facilitating teachers, students, and researchers, the push of generating revenue, and the pull again of institutional strengthening, Ramble Bahamas worked out its balance.

As we might expect, the ability of Ramble Bahamas rapidly to identify and draw upon hidden collections and capture oral narratives so as to extend its array of exhibits can be enhanced through "FDT"'s working collaboratively with other entities. A collaborative approach that supports Ramble might include, for example, liaising with the Ministry of Education, Science, and Technology to enable teachers to take part in building Ramble exhibits. For teachers, the opportunity to join a research team and lead a well-defined research project with support from that team would only strengthen their confidence and skills as researchers and enable them to impart that confidence and 
those skills to their students. For Ramble, the benefit of the arrangement would lie with accelerating the pace at which it develops exhibits, including identifying and exploiting hidden collections and interviewing community elders. Added benefit would lie with solidifying teachers' appreciation of the value of the site as a curricular resource $(S$. Poitier, personal communication, June 30, 2017). Partnering with the Bahamas Ministry of Tourism could also radically accelerate the growth of Ramble. For the Ministry, the exhibits could help the Ministry to market Bahamian history and culture worldwide. Further, entrepreneurial opportunities to which the exhibits point could lend range and depth to the nation's cultural tourism product. For Ramble, the advantage of partnering with the Ministry would lie with "FDT"'s receiving an injection of revenue from the Ministry to enable it to accelerate its research agenda. The same benefit could accrue to Ramble from still another potential public partner: the Bahamas Ministry of Youth, Sports, and Culture. Ramble's exhibits, by providing ample grist for the creative mills of young minds that are intent upon producing factual or fictional narratives in formats ranging from digital animation to wood and stone to dramatic performance, can enliven opportunities for young people to take part in cultural production. In that way the exhibits strengthen the ability of the Ministry of Youth, Sports, and Culture to meet part of its mandate. What is more, Ramble could extend that same collaborative approach beyond public sector partnerships to working in association with independent researchers who are in search of meaningful ways to express their interest in history. Developing Ramble exhibits could provide those independent researchers with a significant outlet for their energies and enable them to demonstrate their capabilities globally. Ramble would benefit, again, from accelerating its rates of collection identification and exploitation, narrator interviewing, and exhibit development. In sum, partnership with selected government ministries as well as with independent researchers can help Ramble to place unearthing hidden collections and generating oral narratives on a faster track.

Fortunately, the University Libraries are already familiar with how collaboration can enhance digital humanities products that bring to light hidden collections and oral narratives. The University Libraries participate as a partner in the Digital Library of the Caribbean (dLOC), which describes itself as being "a cooperative ... that provides users with access to Caribbean cultural, historical and research materials". Currently, through its website (http://www.dloc.com), which is hosted at the University of Florida, dLOC enables visitors to access "2.6 million pages of content related to the Caribbean" that is drawn from "archives, libraries, and private collections" located around the region. One of those libraries is the University of the Bahamas Libraries, which, working through the agency of its Hilda Bowen Library, have posted to dLOC's archive ephemera such as posters, invitations, funeral booklets, and banquet programmes that can advance the research of social historians and others who seek to reconstruct selected aspects of the medical profession in The Bahamas. Again, drawing on research carried out by "FDT" in alliance with the Bahamas Branch of the British Legion, the University Libraries have contributed to the dLOC archive photographs and audio-recorded narratives of 16 Bahamians who served in World War II. This oral history collection, called "No Ordinary Time: Bahamians in the Allied Fight during the Second World War," enables visitors to reconstruct some of the experiences of the military veterans through the veterans' own eyes and allows Bahamian children and teachers and a wider audience to illustrate 
Bahamians' involvement in global events (e.g. http://dloc.com/AA00048254/). Such participation by the University Libraries in a cooperative that supports a digital humanities product may make it easier to win support for creating a collaborative scaffold to build Ramble. In the meantime, in any event, Ramble is doing its part to map and publicize Bahamians' accomplishments and to help us to connect historical developments with one another, consolidate who we are as a people, gauge where our interests lie, acknowledge more fully our human value, and carve out for ourselves more confidently and freely the future that will be ours.

\section{The View from the Hilltop}

What does it all add up to? Looked at in overview, for Bahamians of all socioeconomic, ethnic, and racial descriptions, existential imperatives require that we map our historical experience. Doing that in an intellectually rigorous way, and in a way that produces narratives that illuminate our everyday experience, requires that we augment historical sources that are presently available in public repositories with hidden collections of documents and images and with oral history narratives. That much is plain when we consider the challenge of documenting the experience of Anglophone Bahamians of African descent, for example, whose voices, owing to historical circumstances, are relatively muted in the historical record. In view of the fact that collections of documents and images relating to Bahamians of all backgrounds are rapidly being lost, taking steps swiftly to save these collections is key. Likewise, because bearers of unique historical knowledge are passing on, taking steps swiftly to interview and record them is crucial. Our libraries can play a central role in helping to bring hidden collections to light and in capturing oral narratives. The University Libraries of the
University of The Bahamas exemplify, in their hosting of "From Dat Time": The Oral \& Public History Institute ("FDT"), how Bahamian libraries can intervene to preserve our cultural heritage. The educational value of that kind of institutional initiative is evident from the impact of the educational products of "FDT"'s predecessor, and there is financial value, too, in that kind of undertaking. If we want to accelerate the pace at which we bring hidden collections to light and capture oral narratives, collaboration among those of our institutions which work in or touch the cultural heritage arena can move us forward powerfully. On the front lines of such a coalition should stand the Department of Archives, the University Libraries, and community libraries, especially since through the involvement of community libraries the same institutional collaboration that can accelerate the pace of historical preservation can build our communities as well. To foster this valuable spirit of collaboration, we should create ways for young professionals to work across institutional boundaries. Once we do succeed in unearthing collections of documents and images and capturing oral narratives, we have to find a way to make their contents accessible and yet use them to generate revenue and strengthen our national heritage institutions. Ramble Bahamas (http://www.ramblebahamas.org), a website developed by "FDT" which brings our history to us, shows us one model of balancing these demands. Supported by a collaborative infrastructure, Ramble can increase the pace of identifying hidden collections and of capturing oral narratives; and the participation of the University Libraries in an international cooperative digital humanities venture bodes well for the prospect that Ramble will succeed in helping us to meet those existential imperatives which we face. 


\section{References}

Butler, T., \& Smith, S. (1983). The Bahamas: Social studies for the primary school. London: Collins Caribbean.

Chatterjee, A. (2002). Resource sharing among libraries in a digital era: Role of consortia. Retrieved from http://www.isical.ac.in/ serial/consortia/C BSOR-02.ppt

Collinwood, D. W. (1981). Terra incognita: Research on modern Bahamian society. Journal of Caribbean Studies, 2(1-2), 284297.

Craton, M., \& Saunders, G. (1992). Islanders in the stream, vol. 1. Athens: University of Georgia Press.

Economic Commission for Latin America \& Caribbean. (2004). Hurricanes Frances and Jeanne in 2004: Their impact in the Commonwealth of the Bahamas. Port of Spain, Trinidad and Tobago: United Nations. Retrieved from: http://www.eclac.cl/portofspain/noticias/pa ginas/0/34530/L.23rev2.pdf

Eneas, C. W. (1976). Bain Town. Nassau: Author.

Geertz, C. (1973). The interpretation of cultures. New York: Basic Books

Glinton-Meicholas, P., \& Curry, C. (2004). Bahamians: Immigrants all. Retrieved from http://ufdc.ufl.edu/CA00299017/00001.

Liu, L. G. (2002). The cost function and scale economies in academic research libraries. College \& Research Libraries, 63(5), 406420. https://doi.org/10.5860/crl.63.5.406

Saunders, D. G., \& Carson, E. A. (1980). Supplement to the guide to the records of the Commonwealth of The Bahamas. Nassau, Bahamas: Government Printing.
Thompson, T. L. (2012). Remembering the Contract: Recollections of Bahamians. International Journal of Bahamian Studies, 18, 6-12. https://doi.org/10.15362/ijbs.v18i0.169

Tinker, K. L. (2011). The migration of peoples from the Caribbean to the Bahamas. Gainesville: University Press of Florida.

Turnquest, O. A. (2016). What manner of man is this? The Duke of Windsor's years in The Bahamas. Nassau: Grant's Town Press.

Williams, P. M. (1996). Ethnic minorities in The Bahamas. Journal of the Bahamas Historical Society, 18, 12-20.

Williams, P. M. (1999). Chronological highlights in the history of The Bahamas, 600 to 1900. Nassau: Bahamas Historical Society.

Wisely, J. (2014, February 10). Art's value in society big question in Detroit bankruptcy. Retrieved from http://www.usatoday.com/story/news/natio n/2014/02/10/detroit-bankruptcy$\underline{\operatorname{art} / 5366035 /}$

\section{Appendix A}

Armbrister, C. (1995). Runnin' sheep: A collection of short stories about life in Long Island, Bahamas, 1900-1950. Nassau: Guanima.

Cooper, H. S. (2010). My story ... His glory: The life and experience of a Bahamian son. Bloomington, Indiana: iUniverse.

Cottman, E. W. (1963). Out island doctor. London: Hodder \& Stoughton.

Craton, M. (2002). Pindling: The life and times of the first Prime Minister of The Bahamas. London: MacMillan Caribbean. 
Darling, C. (2002). Sir Clifford Darling: A Bahamian life story. Nassau: Author.

Eneas, C. W. (1976). Bain Town. Nassau: Author.

Fawkes, R. F. (2014). The faith that moved the mountain: A memoir of a life and the times. Nassau, Bahamas: Media Enterprises.

Ford, J. (1992). Reminisces of an island teacher: Life in The Bahamas, 1948-1953. Decatur, IL: White Sound Press.

Galanis, P. C. (2017). All things considered. Nassau, Bahamas: Author.

Hanks, D. (1992). Driven by the stars: The story of Durward Knowles. Nassau, Bahamas: Media Enterprises.

Jenkins, O. C. (2000). Bahamian memories: Island voices of the twentieth century. Gainesville: University Press of Florida.

Johnson, D. (1972). The quiet revolution in The Bahamas. Nassau: Family Islands Press.

Maynard, C. T. (2007). Put on more speed: A Bahamian journey to majority rule and sovereignty. Nassau: I-EASE Publishack.

Poitier, S. (2000). The measure of a man: A spiritual autobiography. New York: HarperCollins.

Robins, F. (2005). Back yonder, 1: The experiences of Flora Robins. Nassau, Bahamas: One Rib.

Saunders, G. (2009). Marguerite Pindling: A biography. Oxford: Macmillan.

Sears, A. M. (2017). A community life: Memoirs of Alfred M. Sears. Nassau, Bahamas: I-Ease Publishack.

Sturrup, F. (2008). A modern perspective of the UBP. Nassau, Bahamas: Variety Communications.

Taylor, H. M. (1987). My political memoirs.
Newell, Iowa: Bireline.

Taylor, P. (2014). A walk through Kemp Road: A community, 1926-2000. Nassau, Bahamas: Polly.

Thompson, L. M. (1995). I wanted wings: The autobiography of Leonard M. Thompson. Decatur, IL: White Sound Press.

\section{Appendix B}

Adderley, R. M. (2006). New negroes from Africa: Slave trade abolition and free African settlement in the nineteenthcentury Caribbean. Bloomington: Indiana University Press

Craton, M. \& Saunders, G. (1992, 1998). Islanders in the stream: A history of the Bahamian people, Vols. I and II. Athens: University of Georgia Press.

Curry, C. (2017). Freedom and resistance: A social history of Black Loyalists in The Bahamas. Gainesville: University Press of Florida.

Hughes, C. A. (1981). Race and politics in The Bahamas. New York: St. Martin's Press.

Johnson, H. (1996). The Bahamas from slavery to servitude, 1783-1933. Gainesville: University Press of Florida.

Saunders, G. (1996). Social life in The Bahamas, 1880s-1920s. Nassau, Bahamas: Rosebud.

Saunders, G. (2003). Bahamian society after emancipation. (3rd ed.). Kingston, Jamaica: Ian Randle.

Saunders, G. (2016). Race and class in the Colonial Bahamas, 1880-1960. Gainesville: University Press of Florida.

Turner, G. (2017). Honoring ancestors in sacred space: The archaeology of an eighteenth-century African-Bahamian cemetery. Gainesville: University Press of Florida. 
() T. L. Thompson \& K. T. Dean, 2017. Journal compilation () International Journal of Bahamian Studies, 2017 